\title{
Educación ambiental: sobre o colapso \\ e a esperanza
}

\section{Environmental education: on collapse and hope}

Teresa Franquesa Codinach ${ }^{1}$, Francisco Heras Hernández ${ }^{2}$ (iD y Pablo Ángel

Meira Cartea ${ }^{3}$ (ID . 1. SCEA-Societat Catalana d'Educació Ambiental, 2. Oficina Española de Cambio Climático, 3. Universidade de Santiago de Compostela (España)

\section{Resumo}

Este artigo recolle e organiza as achegas dos tres autores na mesa redonda que constituíu a sesión de apertura do II Congrés Nacional d'Educació Ambiental de Catalunya, celebrada o 26 de novembro de 2020 e organizado pola Societat Catalana d'Educació Ambiental-SCEA.

\section{Astract}

This article collects and organizes the contributions of the three authors in the round table that constituted the opening session of the II National Congress of Environmental Education of Catalonia, held on November 26, 2020 and organized by the Catalan Society of Environmental Education-SCEA.

\section{Palavras chave}

Educación ambiental; emerxencia climática; colapso; descarbonización; transición ecolóxica.

\section{Key-words}

Environmental education; climate emergency; collapse; decarbonization; ecological transition. 


\section{O contexto. Sinistro total?}

Pódese dicir que a educación ambiental (e o ecoloxismo como movemento político) tivo mala sorte histórica: naceu nos anos 70, xunto co neoliberalismo que se impuxo desde os Estados Unidos e o Reino Unido durante os gobernos de Ronald Reagan e Margaret Thatcher e que se implanta durante as décadas seguintes. Esta corrente ideolóxica exalta unha antropoloxía individualista, cuestiona a intervención do Estado como supervisor do mercado e administrador do ben común e dos bens comúns e oponse a calquera regulación que impida ou limite os intereses do capital, incluídas as normativas ambientais. Aínda agora estamos a vivir as consecuencias da hexemonía deste paradigma, evidente, por exemplo, nas enormes dificultades para definir unha política global que aborde a emerxencia climática, a pesar de que o alcance desta ameaza é ben coñecido pola ciencia, xa que menos, dende mediados do século pasado. Esta conxuntura histórica dificultou o espírito optimista e reformador co que xurdiu a educación ambiental (EA) a finais dos anos sesenta do século $X X$ para xerar unha transformación educativa e social que permita consolidar o coidado do medio ambiente como un piar máis dun Estado Benestar que comezou a ser desmantelado -e aínda o esta a ser- polo tsunami neoliberal.
Un exemplo que simboliza a fonda penetración dos postulados neoliberais é a inclusión nos Obxectivos de Desenvolvemento Sostible (NACIÓNS UNIDAS, 2015) dun "obxectivo de crecemento económico" que afirma "manter o crecemento económico per cápita". O único indicador de cumprimento establecido é a taxa de crecemento anual do PIB, o que significa, na práctica, ignorar os límites e límites biofísicos do planeta ou a desigual distribución de recursos e cargas ambientais entre distintas sociedades. Esta inconsistencia foi resaltada por organizacións tan pouco sospeitosas de adoptar posicións antisistémicas como o Club de Roma: "Pero en ningures da Axenda 2030 se admite que se a construción dos once obxectivos sociais e económicos (do 1 ao 11) se basea nas estratexias de crecemento convencionais implicaría que é practicamente imposible, aínda que só sexa de xeito parcial, frear o quecemento global, deter a sobrepesca oceánica ou a degradación das terras, sen esquecer a perda de biodiversidade. Noutras palabras, asumindo que non hai grandes cambios na forma de definir e controlar a economía, hai enormes contradicións entre os ODS socioeconómicos e os ambientais" (VoN WEIZSÄCKER E WIJKMAN, 2019: 100).

A realidade é que hoxe estamos nun contexto máis insostible que nos anos 70 , superando claramente os límites de habitabilidade da biosfera. Temos un 
desaxuste entre o que producimos e consumimos e a capacidade de resolver os problemas que creamos. Seguramente xa estamos experimentando o colapso. O 22 de agosto (2020), a humanidade, tomada no seu conxunto, superou o consumo de recursos que a terra é capaz de ofrecer ao longo dun ano completo. E, con todo, non se están a cubrir as necesidades básicas dos máis pobres. No ámbito territorial do Estado español, a pegada ecolóxica media é de $4 \mathrm{ha} /$ persoa (cando nos corresponderían 1,2 ha/persoa).

Non obstante, ao mesmo tempo, a resposta institucional está a ser máis importante que nunca. O pasado decembro (o 1112-2020), a Unión Europea revisou os seus obxectivos de redución de emisións de gases de efecto invernadoiro para 2030, pasando do $-40 \%$ ao $-55 \%$, en comparación coas emisións de 1990. Polo que se refire ao Goberno de España, o Consello de Ministros aprobou unha folla de ruta para lograr a neutralidade climática -cero emisións netas de gases de efecto invernadoiro- a mediados deste século. Dentro dunha década, a estratexia de descarbonización do goberno implicaría reducir nun terzo as emisións actuais, contendo o consumo de enerxía, reducindo o uso de combustibles fósiles e aumentando fortemente a produción de enerxía de fontes renovables. Unha das accións máis visibles desta estratexia é o peche efectivo ou previsto das centrais térmicas de carbón: 7 das 15 existentes en España pecháronse definitivamente en 2020. Os gobernos rexional e local tamén están a formular e desenvolver os seus propios plans, introducindo criterios de sostibilidade en áreas estratéxicas como a planificación urbana ou a mobilidade, con procesos de peonalización e restauración da habitabilidade dos espazos urbanos. Tamén percibimos cambios importantes nos comportamentos e estilos de vida a nivel da sociedade: o consumo de carne está caendo en picado, o uso da bicicleta aumenta, a economía social e solidaria tamén medra, coa consolidación das cooperativas de consumo enerxético, os grupos de consumo ecolóxico ou a banca ética. Son cambios relevantes, con impacto, que están a redefinir valores do que é apropiado ou inapropiado no noso estilo de vida desde o punto de vista da sostibilidade social e ambiental e da ética pública. Tamén están xurdindo novos movementos e proxectos sociais de transformación colectiva e transición ecolóxica, onde os procesos educativos xogan un papel fundamental.

\section{As contradicións como incentivo}

Pierre Bourdieu dixo que o problema da socioloxía crítica aplicada á análise rigorosa das estruturas que definen a vida social é que tende a desencantarnos coa 
realidade, xa que axuda a ver o mundo desde un punto de vista que non nos gusta. A EA, cando asume unha posición crítica e cando recoñece a súa natureza política -ao cabo, do que se trata é do tipo de sociedade que queremos construír- tamén pode xerar desencanto e, non poucas veces, frustración entre os e as que nos dedicamos para ela como profesionais ou como activistas. Jacques BOssuet, intelectual e crego francés do século XVII, dixo que "Deus ri dos homes que se queixan das consecuencias mentres consenten as súas causas", un paradoxo que ben podería ser parafraseado para representar 0 escenario que enfronta hoxe a EA: "o mercado ri das persoas que se queixan das consecuencias mentres aceptan as causas". De feito, unha das grandes barreiras da EA realmente crítica nas sociedades occidentais é que a súa ética e os seus referentes sociopolíticos soen ir, inevitablemente, contra os estilos de vida establecidos e o modo de produción-consumo que os alimenta e sostén. Como sinalamos anteriormente, a propia formulación dos ODS non pode evitar estas contradicións estruturais. A primeira meta do ODS 8, sobre "traballo digno e crecemento económico", que anima a "manter o crecemento económico per capita de conformidade coas circunstancias nacionais e, en particular, un crecemento do produto interno bruto de cando menos o $7 \%$ anual nos países menos adiantados", é dificilmente conciliable coa redución de emisións necesaria para mitigar o cambio climático. Asusta -e esgota- no campo da EA a necesidade permanente de loitar polo significado das palabras, superar ambigüidades e dobres discursos, como atopamos cos ODS, que supoñen a contradición de educar para a sostibilidade cun marco que non contempla os límites planetarios e que segue a defender un crecemento sostido como condición para o desenvolvemento humano.

As contradicións poden ser exasperantes, pero tamén poden ser positivas. $\mathrm{Na}$ medida en que se perciben contradicións, algo chía. Entramos nun proceso de transición, de cambio e, a medida que avanzamos, as contradicións serán cada vez máis evidentes. A inercia do sistema fará que algúns elementos contraditorios permanezan por un tempo, mentres que outros comezarán a cambiar. Debemos facer un uso intelixente das contradicións, aprender a recoñecelas e loitar contra a desinformación de xeito positivo. Aproveitalos para interrogalos e non normalizalos.

\section{Demolición e construción}

A EA ten dúas misións que parecen opostas: demoler algo que non funciona e construír algo que queremos que funcione. Presentado en termos educativos, diante da crise socio-ambiental, o desaprender 
é tan importante como o aprender. Ademais de demoler (revisar criticamente as ideas, os hábitos e os modos de vida establecidos), temos que construír. Hai que explorar novas formas de ver o futuro común e debemos participar na súa creación. Na EA afrontamos o reto de combinar un espírito crítico e a capacidade de contribuír ao cambio. Michela MAYER suxeriu hai moitos anos a fórmula "ollada crítica e linguaxe de posibilidade": ver o que non funciona e falar do que se pode facer. Pero é unha proposta que require saber aceptar a complexidade, evitar os esquemas do branco ou negro e aprender a amar os grises, esa gama que tan pouco nos gusta. A chave é atopar espazos entre o demoler e o crear.

Hai un elemento de esperanza: os procesos transformadores abren novos escenarios, espazos para o cambio, xanelas de oportunidade, novas formas de facer as cousas, de gobernarse. Pindado, Martí e Rebollo (2002) lembran que o principal motor do cambio son as persoas e as persoas cambian a través dos procesos educativos: "a práctica móstranos cada día que o principal instrumento para o cambio son as persoas. Somos nós os que cambiamos e, ao facelo, conseguimos cambiar as cousas. Chamamos educativo a este tipo de cambios e, polo tanto, para que as cousas cambien, debemos educarnos; porque estamos falando do cambio da xente". Dado que a educación está no centro da transformación, a EA debe unirse a procesos de transformación e xerar así aprendizaxe social. Somos nós, a xente, quen temos que cambiar para que todo cambie.

Agora, é difícil que unha persoa cambie soa, nin unha soa persoa fai que as cousas cambien, aínda que pode influír e impulsar con eficacia para difundir ideas. A xente cambia máis facilmente se a nosa contorna nos invita e o facilita. Por iso é fundamental establecer ambientes estimulantes nos que as persoas se sintan satisfeitas cando actuamos para contribuír a obxectivos compartidos. Un exemplo podería ser a rede Barcelona + Sostenible, creada en torno ao Compromiso Cidadán coa Sostibilidade. Nas súas dúas versións consecutivas (2002-2012 e 2012-2022) este decálogo de obxectivos compartidos reuniu a máis de 1.500 organizacións que deseñan o seu propio plan de acción, comparten experiencias e boas prácticas e desenvolven proxectos conxuntos.

Debemos crear este espazo intelixente entre demoler e construír e facilitar contextos onde o cambio individual sexa posible e onde se funda no cambio colectivo. Construír, sempre que sexa posible, espazos de coherencia, onde se comprobe que as accións e os cambios individuais tamén poden ter unha dimensión colectiva que mellore a vida en común. Crear esferas públicas alternativas, espazos para o cambio, contextos sociais ou microcontextos onde o cambio sexa 
acollido e alentado, comunidades de innovación nas que a xente se sinta inmersa nun ambiente que pon en práctica o que predica e onde non nos sentimos estrañas polas nosas eleccións e hábitos. Pode ser unha cooperativa de consumo ou coche compartido, unha escola sostible, unha asociación veciñal que cree un banco do tempo, unha iniciativa para a recuperación de excedentes e o comercio que se suma e o fai saber aos seus clientes e tantos outros exemplos que existen, por fortuna. Temos que valorar estes espazos de coherencia que xa existen ao noso redor, onde é posible vivir diferentes estilos de vida "sen ir en contra". Nestas contornas conflúen os cambios individuais e colectivos.

A dimensión colectiva é esencial para a EA, para xerar un diálogo crítico e consciente entre o individual e o colectivo. Autores como Foucault ou Bourdieu afirman que a sociedade non é algo externo nós, que está encarnada no noso eu. E é a través da educación que podemos desenvolver a capacidade de auto-socio-análise -para comprender como as estruturas sociais nos condicionan e para cuestionar esas imposicións culturais que nos fan insostibles colectivamente- como unha das chaves para proxectar o cambio da esfera persoal á dimensión social. O persoal é político porque o persoal tamén é social.

\section{Ser un motor de cambio colectivo}

Moitas persoas que participan na EA víronse tradicionalmente como transmisores de mensaxes, pero na visión que temos do noso traballo hoxe en día, os educadores e as educadoras ambientais deben ser facilitadoras do cambio para involucrar e empoderar ás persoas en proxectos de transformación social.

Como educadoras e educadores ambientais debemos traballar en dous niveis que retroalimentan:

- No nivel do que pensamos (sementando ideas alternativas, axudando a construír un novo marco de pensamento) e

- No nivel do que facemos (prácticas): xerar comunidades de cambio (cooperativas de consumidores, escolas comprometidas coa sustentabilidade, movementos de salvagarda dos bens comúns etc.) onde se recoñezan as boas prácticas e se nutran da praxe as boas ideas.

Estendeuse o mito de que os procesos participativos son espontáneos. Precisamente é o contrario: son procesos complexos que deben organizarse e estruturarse. E aquí reside o papel dos educadores e as educadoras ambientais. O noso papel é motivar e catalizar os procesos de cambio, estimulando a 
participación das persoas, identificando onde están as dificultades e acompañando estratexias sociais para superalas. Os educadores e as educadoras ambientais deben motivar e facilitar procesos de transformación social, procesos onde a comunidade recoñece un desafío na súa viaxe cara á sostibilidade e ponse en marcha para afrontalo a través do cambio.

Estimular a aprendizaxe a través da participación nestes proxectos é laborioso e esixente para os educadores, que deben asumir tarefas como:

- saber convidar a participar, facer que a xente sinta que crear un ambiente máis interesante está nas súas mans e é a súa responsabilidade;

- procurar a información necesaria para un bo coñecemento da realidade con toda a súa complexidade;

- estimular unha mirada crítica, pero tamén a creatividade;

- fomentar a apertura de horizontes e o traballo en rede;

- adquirir habilidades na coordinación de proxectos interdisciplinares e dominar as ferramentas que farán posible racionalizar os procesos e axudar a levar a unha conclusión exitosa;

- pechar o ciclo avaliando os resultados, dar feedback aos participantes e incorporar as aprendizaxes que mellorarán o proceso.
A participación é un fin e un medio na EA. O coñecemento pode levar á acción, pero a acción tamén pode levar ao coñecemento.

\section{A educación ambiental na escola}

En canto ao sistema educativo formal, a necesidade de adaptar o currículo aos retos e problemas do século XXI está a xerar un campo de batalla cultural e económico onde conflúen moitos intereses en conflito. A presión sobre o sistema educativo é tan grande que é difícil acomodar novos conceptos e novas demandas sociais. Por exemplo, cinco anos despois do Acordo de París, as iniciativas para incorporar a emerxencia climática aos marcos curriculares oficiais son anecdóticas e moi limitadas na súa ambición pedagóxica, social e ambiental. Non obstante, tamén vemos como están xurdindo novas oportunidades no ámbito educativo, con iniciativas como os Fridays for Future, as escolas sostibles, os camiños escolares, a transformación dos patios escolares, os cambios na xestión e funcionamento dos centros etc., que patrocinan contextos de coherencia e traballan para estendelos na comunidade educativa e nos seus escenarios sociais de referencia.

A transversalidade curricular da EA segue sendo unha idea válida pero, a efectos prácticos, habería que pensar en acoutar 
unha parte do currículo -obxectivos, espazos, tempos, recursos, materiais, docentes-e integrar a emerxencia climática na práctica educativa, en todos as súas dimensións. O cambio climático non debe ser visto como un tema ou materia máis, senón como un problema que se debe afrontar na súa complexidade durante a educación obrigatoria, con tempos e espazos curriculares específicos. O protagonismo da emerxencia climática na axenda curricular tamén enviaría un sinal moi poderoso á sociedade sobre cales son os temas chave, obrigaríanos a repensar as prioridades e reflectir sobre como tratar con elas no sistema educativo.

A nova Lei orgánica de educación no Estado Español (a LOMLOE) toma os ODS como referencia e asume o marco do desenvolvemento sostible, pero aínda está por ver se o seu despregue, principalmente a nivel rexional, será unha oportunidade para aliñar o sistema educativo cos retos da emerxencia climática-que se menciona explicitamente na versión final da lei-, co obxectivo de que as novas xeracións -que son inevitablemente as xeracións do cambio climático- poidan enfrontarse aos escenarios que virán. Non obstante, nos principios que estruturan o novo marco legal faltan ideas fundamentais en EA, como a noción de dependencia ecolóxica e a conciencia dos límites e fronteiras planetarias. Unha ausencia que é imprescindible corrixir nos documentos que deberán despregar a nova Lei.

\section{Unha profesión de futuro?}

O campo da EA é complexo, debido á historia que o constituíu. Nel conviven perfís persoais e profesionais de orixes moi diferentes (ciencias naturais, ciencias sociais como a pedagoxía, persoas sen titulación académica pero formadas nos movementos ecoloxistas etc.). Tomando como referencia a teoría de BouRdieu dos campos sociais, a EA podería considerarse como un "transcampo" (BouRdieu preferiría o concepto de "subcampo") no que os axentes que o habitan e o constitúen oscilan entre os campos das ciencias ambientais/naturais e educativas/sociais, que operan con diferentes lóxicas de poder, con funcións sociais e profesionais case sempre suxeitas a condicións de precariedade e subsidiariedade: o educativo é subsidiario nas políticas ambientais e o ambiental é subsidiario nas políticas educativas. As condicións precarias -en termos económicos, de recoñecemento profesional e de recoñecemento social- da maior parte dos profesionais da EA contrastan co perfil académico universitario da maioría das persoas que se dedican a ela.

Resulta chocante -pero consecuente co papel contracultural da EA- que se trate dunha profesión que se considera esencial para avanzar na transición ecolóxica (unha profesión do futuro) e que sexa, simultaneamente, unha profesión 
precaria, precarizada e invisible. En España houbo unha falta histórica crónica dunha política pública de EA sólida, con financiamento específico, acompañada da creación de estruturas institucionais especializadas e cunha proxección a medio e longo prazo. Os momentos máis esperanzadores, arredor da redacción do Libro branco sobre educación ambiental en España, hai dúas décadas, tiveron un desenvolvemento desigual no mosaico das comunidades autónomas. En xeral, prevaleceu a incongruencia entre os marcos estratéxicos aprobados (a práctica totalidade das comunidades autónomas aprobaron estratexias territoriais de EA durante os primeiros cinco anos deste século) e a falta de plans para financiar e apoiar a súa concreción con recursos e programas educativos concretos.

Ademais de ser unha profesión en si mesma, a EA tamén é unha ferramenta que outros profesionais empregan nas súas tarefas. De feito, está presente en moitas profesións que normalmente non identificamos co núcleo duro de EA. É importante combinar as dúas dimensións e, por suposto, débese dar máis valor á EA e deberían fortalecerse tanto aos educadores e ás educadoras ambientais profesionais como a outros axentes que a practican.

Gustaríanos identificarnos como un movemento social ou cultural, pero aínda que o somos na medida en que propoñemos un cambio social e cultural, non estamos suficientemente organizados. Se temos algunha posibilidade de xerar cambios reais, será sumando os esforzos do propio colectivo cos doutras forzas que perseguen transformacións converxentes nos ámbitos político, social, económico ou cultural. Como xerar estas alianzas, definir estratexias compartidas e gañar forza?

A EA é algo máis que un campo profesional e ten uns límites moi difusos, que deberían aproveitarse para tecer estas alianzas. Pero a realidade é que os activistas dos Fridays for Future pensaban que estaban "sos", que non tiñan referencias. É moi posible que haxa un problema de renovación e continuidade xeracional, xa que os novos grupos ecoloxistas parecen desconectados e non utilizan a mesma terminoloxía. É preocupante que as novas xeracións que promoven a educación ecosocial ignoren ou "rexeiten" a traxectoria da EA -que, por outra banda, está marcada por luces e sombras- e descoñecen ou non se senten implicadas no que se fixo ata agora. Isto provoca unha perda de aprendizaxes e experiencias previas anteriores, e é un problema difícil de resolver: está desconectado o "noso discurso"? Ou é que as novas xeracións non queren asumilo porque o identifican cun mundo que non senten como seu ou porque asumen que a insostibilidade contemporánea tamén é un fracaso da EA? 


\section{Ansiedade e esperanza}

Unha das cuestións sobre as que máis avanzamos en EA é en recoñecer a importancia dos aspectos emocionais. O cambio climático e outros problemas ambientais son tristes, sinistros e incluso deprimentes. Isto xera respostas emocionais moi negativas, que poden traducirse en bloqueo ou inhibición. Para aprender a xestionar esta dimensión emocional, cada vez é máis importante comprender como funcionan as respostas de autoxustificación, que serven para tranquilizarnos e evitar os sentimentos de culpa ante a crise ambiental (negación da realidade, trasladar a responsabilidade aos demais, cambiar o foco, pensar que a contribución individual serve para pouco etc.).

O único xeito de contrarrestar os niveis de ansiedade cada vez máis paralizantes, que socavan a vontade ou capacidade de moita xente para participar, é a través do cultivo da esperanza real, con contido e dirección. Non é a dicir que "todo estará ben" senón axudar ás persoas a realizar o seu poder para tomar accións significativas que marcarán a diferenza.

Os mozos son moi conscientes da súa vulnerabilidade. Como educadores e educadoras, depende de nós aliñarnos coa súa coraxe e vontade de loita. Que saiban que non están sos. Os promotores de movementos como Fridays For Future tenden a ser escépticos sobre o futuro, pero aínda así actúan e intentan enfocar as súas propostas e accións positiva e construtivamente.

A EA pódese dotar de moitos instrumentos e non sempre teñen que ser de denuncia ou enfocados exclusivamente á racionalidade e á xestión e transposición do coñecemento científico. Tamén se pode usar o sentido do humor e recorrer ás linguaxes e ás experiencias artísticas (teatro, música, artes plásticas, etc.) como pontes para alcanzar emocións e sentimentos.

Desde unha perspectiva realista e lonxe de negar a escala dos problemas, compartimos unha visión do futuro con esperanza (non hai pedagoxía sen esperanza). Esta esperanza reside na dignidade da vida humana, para reducir os impactos e minimizar os desequilibrios que poden multiplicar e agravar o sufrimento da maior parte da humanidade.

Na práctica do día a día será bo centrarse no que podemos facer e no que temos que facer. E seguir reflectindo como colectivo para facernos máis fortes sendo máis conscientes das nosas debilidades.

Temos novas oportunidades para aprender e cambiar, e queremos facelo. Sabemos que non só é posible combinar aprendizaxe e transformación social, senón que é 
esencial. Trátase de seguir traballando, cunha actitude positiva. Ante distopías desesperadas, debemos construír novos horizontes utópicos, se é necesario dende unha dignidade desconsolada (en palabras de Jorge RIECHMANN), para vivir dignamente e gozar da vida.

\section{Referencias bibliográficas}

NACIONES UNIDAS (2015). Transformar nuestro mundo: la Agenda 2030 para el Desarrollo Sostenible. Resolución aprobada por la Asamblea General el 25 de septiembre de 2015.

PINDADO, F.; MARTí, J.; REBOLLO, O. (2002). Eines per a la participació ciutadana: Bases, mètodes $i$ tècniques. Barcelona: Diputació de Barcelona.

VON WEIZSÄCKER, E.; WIJKMAN, A. (2019). Come on! Capitalismo, cortoplacismo, población y destrucción del planeta. Barcelona: Deusto. 